Section Editor

Mitchell S.V. Elkind,

MD, MS

Manoj K. Mittal, MBBS

Tamika M. Burrus, MD

Norbert G. Campeau, MD

Laurence J. Eckel, MD

Alejandro A. Rabinstein, MD

Eelco F.M. Wijdicks, $\mathrm{MD}, \mathrm{PhD}$

Correspondence to

Dr. Mittal:

mittal.manoj@alumni.mayo.edu

Pearls \& Oy-sters:

\title{
Good recovery following cerebral fat embolization with paroxysmal hyperactivity syndrome
}

\section{PEARLS}

- Cerebral fat embolism syndrome (FES) most often presents with gradual decline in level of consciousness and worsening motor responses.

- MRI shows innumerable punctate foci of restricted diffusion in a "starfield" pattern, which subsequently coalesce into confluent lesions.

- Paroxysmal sympathetic hyperactivity (PSH) after FES may not be a poor prognostic sign and good recovery can occur.

\section{OY-STERS}

- FES is a triad of CNS dysfunction (rapidly developing coma), petechial hemorrhage (typically on upper body), and acute pulmonary injury (hypoxemia, tachypnea).

- PSH syndrome is characterized by episodic fever, diaphoresis, hypertension, tachycardia, tachypnea, and rigidity. PSH has traditionally been observed in traumatic brain injury patients and is generally associated with a poor outcome.

CASE 1 A 21-year-old previously healthy man had a right closed midshaft femur and patella fracture from a motor vehicle accident (figure, A). Four hours later, he underwent right knee irrigation and debridement followed by a proximal tibial traction pin placement. Ten hours after this procedure, he became confused, agitated, hypoxemic (oxygen saturation 60\%), hypotensive (blood pressure $86 / 58 \mathrm{~mm} \mathrm{Hg}$ ), and tachycardic (pulse $140 / \mathrm{min}$ ). He was now comatose with spontaneous extensor responses. Skin petechiae were noted. Chest CT showed bilateral pulmonary edema. Transthoracic echocardiogram (TTE) showed dyssynchronous interventricular septum and elevated right ventricular systolic pressure consistent with acute pulmonary hypertension. For several days, he remained comatose and developed episodes of fever, tachycardia, and profuse sweating. $\mathrm{He}$ was diagnosed with PSH and received propranolol, gabapentin, and clonidine. To better control these episodes, lorazepam, fentanyl, and morphine were also administered. Brain MRI on day 5 showed multiple diffuse hypointense foci on susceptibility-weighted sequence (SWI) and innumerable foci of reduced diffusion in a "starfield" pattern, compatible with fat embolism (figure, B and C).

He started to open his eyes at 2 weeks and eventually made a remarkable recovery. On a follow-up MRI there was evolution of the punctate restricted diffusion to confluent signal change in the caudate and splenium of the corpus callosum (figure, D). Neuropsychometric testing showed impairments in cognitive speed and executive function. At 12 months follow-up, he was able to work part time.

CASE 2 A 42-year-old man was shot in the left foot by his 12-year-old son during a hunting trip. X-ray showed multiple fractures of the left calcaneus associated with soft tissue swelling (figure, E). Four hours later, his blood pressure transiently declined to $83 / 55 \mathrm{~mm} \mathrm{Hg}$. His arterial blood gas showed pH 7.39, $\mathrm{PO}_{2} 158 \mathrm{~mm} \mathrm{Hg}, \mathrm{PCO}_{2}$ $37 \mathrm{~mm} \mathrm{Hg}$, and $\mathrm{FIO}_{2} 40 \%$ with an increased arteriolaralveolar gradient of 81 . He was groaning, opening his eyes spontaneously, and not tracking. There was increased muscle tone, hyperreflexia, and bilateral Babinski signs. He gradually became less responsive and 5 hours later developed extensor posturing. He was intubated for airway protection. Chest $\mathrm{x}$-ray was normal. Brain MRI performed 30 hours later showed scattered foci of reduced diffusion in a starfield pattern (figure, F). TTE showed intrapulmonary shunting. He became tachycardic (pulse up to 148 beats $/ \mathrm{min}$ ) and febrile $\left(39^{\circ} \mathrm{C}\right)$, and manifested profuse sweating. He was treated with gabapentin, hydromorphone, and metoprolol. He had spontaneous eye opening the next day. Follow-up MRI after the first week demonstrated near resolution of prior diffusion-weighted imaging (DWI) lesions (figure, G) with continuous improvement at 4 weeks (figure, $\mathrm{H}$ ). He was transferred to a nursing home. The patient improved slowly and after 6 months he was living at home with family. His residual deficits included problems with speech, memory (short and long term), irritability, left upper extremity spasticity, left ulnar compression neuropathy, peripheral neuropathy, and antalgic gait.

DISCUSSION Our patients merit attention because despite worrisome findings on examination (extensor posturing and severe episodes of PSH) and MRI, they

From the Departments of Neurology (M.K.M., A.A.R., E.F.M.W.) and Radiology (N.G.C., L.J.E.), Mayo Clinic, Rochester, MN; and the Department of Neurology (T.M.B.), UCLA, Los Angeles, CA.

Go to Neurology.org for full disclosures. Funding information and disclosures deemed relevant by the authors, if any, are provided at the end of the article. 

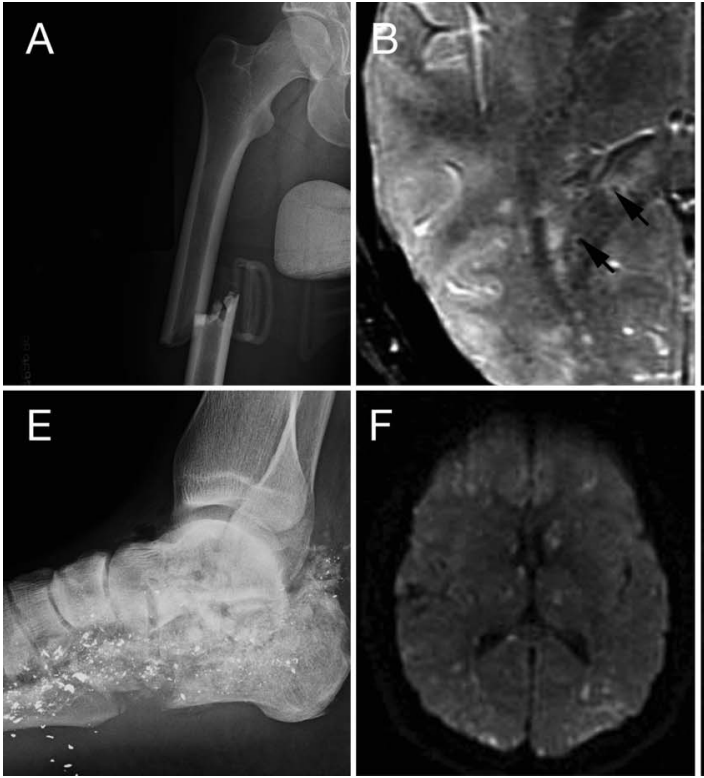
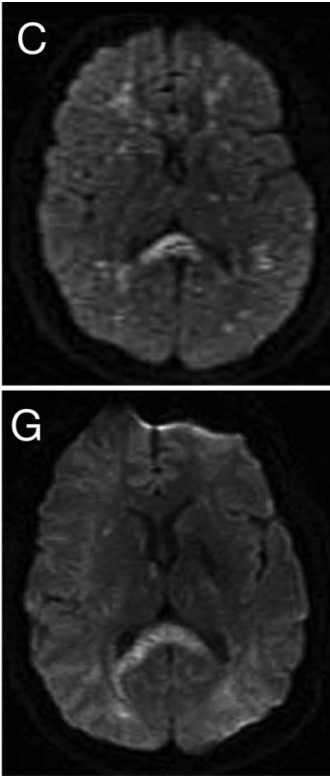
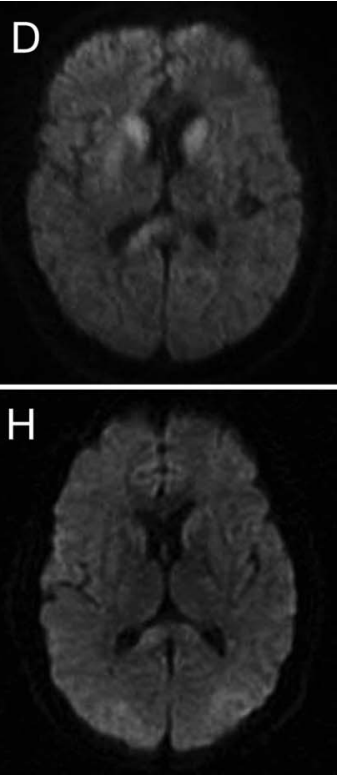

Upper row (case 1): Radiograph of the right leg shows closed midshaft femur fracture (A); day 5, axial susceptibilityweighted imaging sequence shows multiple punctate foci of hypointense signal throughout the brain (marked by black arrow) (B); multiple foci of restricted diffusion (starfield pattern) in diffusion-weighted imaging sequence (DWI) (C) and follow-up MRI on day 23 show resolution of some lesions in DWI sequence (D). Lower row (case 2): Radiograph of the left foot and calcaneus shows innumerable tiny metallic shot fragments in the soft tissues and bones and multiple fractures of the calcaneus associated with soft tissue swelling (E); first MRI done on day 1 shows multiple areas of restricted diffusion in DWI sequence in characteristic starfield pattern (F); follow-up MRI on day 7 shows progression of tiny lesions to confluent pattern (G); follow-up MRI on day 30 shows marked resolution of the cytotoxic edema $(\mathrm{H})$.

had good recovery. PSH in our patients may be explained by multifocal lesions of thalamus and brainstem leading to the autonomic nervous system dysregulation. ${ }^{1}$

FES is mostly seen following long bone fractures, but in only $1 \%$ of patients. FES requires pressurization of fat to enter the venous system. ${ }^{2}$ Our second patient did not have any long bone fracture to explain his FES. The possible mechanism here was disruption of calcaneus vessels, mobilization of calcaneal marrow fat with or without heel pad fat, and pressurization from the acute gunshot injury and local soft tissue swelling. ${ }^{3} \mathrm{He}$ also had FES without pulmonary edema but there was a transpulmonary shunt on TTE. The delay in neurologic or pulmonary presentation is a result of massive and prolonged embolic shower eventually overwhelming the pulmonary and cerebral reserve. ${ }^{4}$

Arteriolar occlusions by fat emboli are imaged as numerous tiny hyperintense lesions (starfield pattern) on DWI sequence and represent cytotoxic edema. A SWI sequence can show diffuse hypointense lesions that represent microhemorrhages. SWI can be useful as it may be the only MRI sequence showing microhemorrhages. ${ }^{5}$ Restricted diffusion in the splenium of the corpus callosum (cases 1 and 2) and caudate nucleus (case 1 only) can be similar to global hypoxic ischemic injury, but after FES is not associated with a poor outcome. ${ }^{6}$ In both patients, MRI improvement seemed to parallel clinical improvement. ${ }^{7}$ Long-term outcome after FES — when defined by coma and starfield patterns on MRI determined by our literature review of all published cases from 1990 to 2012 showed that 57/75 (76\%) patients had good outcome. However, a possible publication bias in favor of cases with better outcome and the variable follow-up intervals among reported cases need to be considered when interpreting this literature.

PSH syndrome may have similarities with early sepsis, pulmonary embolism, hyperthyroidism, pheochromocytoma, serotonin syndrome, neuroleptic malignant syndrome, malignant hyperthermia, sympathomimetic agents or anticholinergic agents overdose, extreme form of alcohol withdrawal, meningoencephalitis, or autonomic dysreflexia seen with acute spinal cord injury. Pertinent history, examination, and laboratory testing (creatine kinase, serial serum lactate, and repeated blood cultures) may help to exclude these mimickers, which are less paroxysmal, less hyperadrenergic, and mostly progressive in nature. Treatment of cerebral FES and PSH is mainly supportive. Opioids, $\beta$-blockers, gabapentin, and $\alpha 1$ agonists are some of the options available to manage PSH. Corticosteroids may have a role in preventing FES, but there is no proven effect after embolization has occurred. ${ }^{?}$

\section{AUTHOR CONTRIBUTIONS}

Manoj K. Mittal: conceptualization of study, data gathering and analysis, drafting and revision of manuscript. Tamika Burrus: conceptualization of study, data gathering and analysis, drafting and revision of manuscript. 
Norbert G. Campeau: revision of manuscript. Laurence Eckel: revision of manuscript. Alejandro Rabinstein: revision of manuscript. Eelco F. Wijdicks: conceptualization of study, revision of manuscript, senior author.

\section{STUDY FUNDING}

No targeted funding reported.

\section{DISCLOSURE}

The authors report no disclosures relevant to the manuscript. Go to Neurology.org for full disclosures.

\section{REFERENCES}

1. Perkes I, Baguley IJ, Nott MT, Menon DK. A review of paroxysmal sympathetic hyperactivity after acquired brain injury. Ann Neurol 2010;68:126-135.

2. Robert JH, Hoffmeyer P, Broquet PE, Cerutti P, Vasey H. Fat embolism syndrome. Orthop Rev 1993;22:567-571.

3. Samarasekera S, Mazibrada G. Shot in the foot. Pract Neurol 2012;12:382-383.
4. Christie J, Burnett R, Potts H, Pell A. Echocardiography of transatrial embolism during cemented and uncemented hemiarthroplasty of the hip. J Bone Joint Surg Br 1994;76:409-412.

5. Zaitsu Y, Terae S, Kudo K, et al. Susceptibility-weighted imaging of cerebral fat embolism. J Comput Assist Tomogr 2010;34:107-112.

6. Bianchi MT, Sims JR. Restricted diffusion in the splenium of the corpus callosum after cardiac arrest. Open Neuroimag J 2008;2:1-4.

7. Takahashi M, Suzuki R, Osakabe Y, et al. Magnetic resonance imaging findings in cerebral fat embolism: correlation with clinical manifestations. J Trauma 1999;46:324-327.

8. Parizel PM, Demey HE, Veeckmans G, et al. Early diagnosis of cerebral fat embolism syndrome by diffusion-weighted MRI (starfield pattern). Stroke 2001;32:2942-2944.

9. Bederman SS, Bhandari M, McKee MD, Schemitsch EH. Do corticosteroids reduce the risk of fat embolism syndrome in patients with long-bone fractures? A meta-analysis. Can J Surg 2009;52:386-393. 


\section{Neurology}

\section{Pearls \& Oy-sters: Good recovery following cerebral fat embolization with paroxysmal hyperactivity syndrome}

Manoj K. Mittal, Tamika M. Burrus, Norbert G. Campeau, et al.

Neurology 2013;81;e107-e109

DOI 10.1212/WNL.0b013e3182a6ca3e

This information is current as of September 30, 2013

\section{Updated Information \&} Services

References

Subspecialty Collections

\section{Permissions \& Licensing}

Reprints including high resolution figures, can be found at: http://n.neurology.org/content/81/14/e107.full

This article cites 9 articles, 2 of which you can access for free at: http://n.neurology.org/content/81/14/e107.full\#ref-list-1

This article, along with others on similar topics, appears in the following collection(s):

\section{Coma}

http://n.neurology.org/cgi/collection/coma

Critical care

http://n.neurology.org/cgi/collection/critical_care

Embolism

http://n.neurology.org/cgi/collection/embolism

MRI

http://n.neurology.org/cgi/collection/mri

Prognosis

http://n.neurology.org/cgi/collection/prognosis

Information about reproducing this article in parts (figures,tables) or in its entirety can be found online at:

http://www.neurology.org/about/about_the_journal\#permissions

Information about ordering reprints can be found online: http://n.neurology.org/subscribers/advertise

Neurology ${ }^{\circledR}$ is the official journal of the American Academy of Neurology. Published continuously since 1951, it is now a weekly with 48 issues per year. Copyright @ 2013 American Academy of Neurology. All rights reserved. Print ISSN: 0028-3878. Online ISSN: 1526-632X.

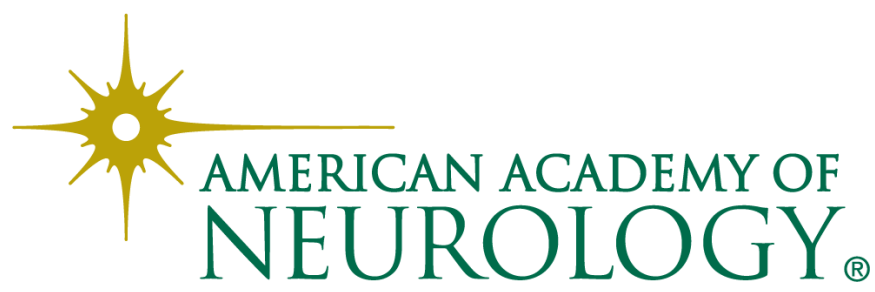

